\title{
Bone density in women receiving depot medroxyprogesterone acetate for contraception
}

\author{
Tim Cundy, Margaret Evans, Helen Roberts, Diana Wattie, Ruth Ames, Ian R Reid
}

\begin{abstract}
Objective-To determine if the use of the injectable contraceptive depot medroxyprogesterone (DMPA), which reduces ovarian oestrogen production, is associated with changes in bone density.

Design-Population study. DMPA users were compared with two control groups selected from larger population studies and individually matched for several putative determinants of bone density (age, race, body mass index, and years of oestrogen deficiency). Controls and DMPA users were matched without prior knowledge of their bone density measurements.
\end{abstract}

Setting - Teaching hospital and community family planning clinics.

Subjects-30 current users of DMPA with a minimum five years' previous use, 30 premenopausal controls, and 30 postmenopausal controls.

Main outcome measure-Lumbar spine and femoral neck bone mineral density assessed by dual energy $x$ ray absorptiometry.

Results-Compared with premenopausal controls matched for age, race, and body mass index, DMPA users had significantly reduced bone density in the lumbar spine (mean difference $7 \cdot 5 \%$ (95\% confidence interval $1.9 \%$ to $13.1 \%), p=0.002)$ and in the femoral neck $(6 \cdot 6 \%,(0 \cdot 8 \%$ to $12 \cdot 3 \%), p=0 \cdot 007)$. Compared with postmenopausal controls matched for body mass index and duration of oestrogen deficiency, DMPA users had greater bone density in the lumbar spine $(8.9 \%(4.3 \%$ to $13.5 \%), p=0.001)$, but in the femoral neck the difference in bone density was less $(4.0 \%(-0.4 \%$ to $8 \cdot 5 \%), p=0.04)$.

Conclusions-Women using DMPA have bone density values intermediate between those of normal premenopausal and postmenopausal controls; thus, the degree of oestrogen deficiency induced by DMPA may have an adverse effect on bone density.

Department of Medicine Auckland Hospital, Auckland 1, New Zealand Tim Cundy, MD, senior lecturer

Margaret Evans, BSC, senior research officer

Diana Wattie, SRN, nurse in charge

Ruth Ames, technician

Ian R Reid, MD, senior lecturer

Family Planning

Association of New

Zealand, Auckland 1, New

Zealand

Helen Roberts, MB, medical director

Correspondence to:

Dr Cundy.

BMF 1991;303:13-6 injectable progestogen, is a contraceptive that is widely used in many parts of the world, including New Zealand, where users account for $7 \%$ of all visits to family planning clinics. It works primarily by inhibiting secretion of pituitary gonadotrophin. Ovulation stops, and with continued use most women become amenorrhoeic. Ovarian production of oestradiol and oestrone is also suppressed. Women using DMPA long term have serum oestradiol concentrations in the range normally found in the early to middle follicular phase ${ }^{8-10}$ Because of this partial oestrogen deficiency these women might be expected to become osteopenic. As this possibility has not previously been investigated, we studied women using DMPA for contraception to determine whether its long term use is associated with changes in bone mineral density.

\section{Subjects and methods}

Thirty women (24 of European origin, six of Maori or Pacific Island origin) aged 25-51 years who had been using DMPA for a minimum of five years were recruited by advertising in community family planning clinics. None had any history of metabolic bone disease or had conditions or took drugs known to affect bone and mineral metabolism, although many were cigarette smokers (table I). The duration of DMPA use ranged from 5 to 20 years (median 10). Twenty four women had used DMPA continuously, but six had taken one or two short breaks ( 1.5 years or less) to have children. The stated duration of DMPA use in these women excludes these intervals. At the time of study all were receiving injections every 12 weęks of $150 \mathrm{mg}$ DMPA (Depo-Provera, Upjohn) and all reported continuous amenorrhoea

TABLE I - Characteristics of three groups of women whose bone density was measured

\begin{tabular}{|c|c|c|c|}
\hline & $\begin{array}{l}\text { Premenopausal } \\
\text { controls } \\
(\mathrm{n}=30)\end{array}$ & $\begin{array}{c}\text { DMPA } \\
\text { users } \\
(\mathbf{n}=30)\end{array}$ & $\begin{array}{l}\text { Postmenopausal } \\
\text { controls } \\
(\mathbf{n}=30)\end{array}$ \\
\hline $\begin{array}{l}\text { No }(\%) \text { cigarette smokers } \\
\text { Median (range) age (years) } \\
\text { Median (range) years of }\end{array}$ & $\begin{array}{c}3(10) \\
42 \cdot 5(25-52)\end{array}$ & $\begin{array}{c}12(40) \\
43 \cdot 5(25-51)\end{array}$ & $\begin{array}{c}5(17) \\
57 \cdot 0(45-68)\end{array}$ \\
\hline $\begin{array}{l}\text { oestrogen deficiency } \\
\text { Median (range) body mass } \\
\text { index }\end{array}$ & $\begin{array}{c}24 \cdot 1 \\
(18 \cdot 5-37 \cdot 2)\end{array}$ & $\begin{array}{c}10(5-20) \\
24 \cdot 0 \\
(18 \cdot 4-38 \cdot 3)\end{array}$ & $\begin{array}{c}7(5-22) \\
24 \cdot 1 \\
(20 \cdot 2-39 \cdot 6)\end{array}$ \\
\hline
\end{tabular}

Comparisons were made with two control groups of women not using DMPA. Firstly, from a total of 69 normal premenopausal women volunteers having their bone density measured we selected a control group of 30 to form matched pairs with the DMPA users. We matched these subjects as closely as possible for age, body mass index, and ethnic origin without knowledge of bone density measurements. In this matching process we gave primacy to matching for body mass index as it was the variable most closely correlated with bone density in the DMPA users (table II). The mean difference between DMPA users and premenopausal controls was $0 \cdot 14$ (SD 0.85$) \mathrm{kg} / \mathrm{m}^{2}$ for body mass index and $0.23(5 \cdot 7)$ years for age. Secondly, from a total of 67 normal postmenopausal women volunteers having 


\begin{tabular}{|c|c|c|c|c|c|}
\hline & $\begin{array}{l}\text { Premenopausal } \\
\text { controls }\end{array}$ & p Value & $\begin{array}{c}\text { DMPA } \\
\text { users }\end{array}$ & p Value ${ }^{\star}$ & $\begin{array}{l}\text { Postmenopausal } \\
\text { controls }\end{array}$ \\
\hline \multicolumn{6}{|l|}{ Serum biochemistry: } \\
\hline Calcium concentration $(\mathrm{mmol} / \mathrm{l})$ & $2 \cdot 28(0 \cdot 06)$ & $0 \cdot 21$ & $2 \cdot 31(0 \cdot 07)$ & $0 \cdot 001$ & $2 \cdot 37(0 \cdot 06)$ \\
\hline Phosphate concentration $(\mathrm{mmol} / \mathrm{l})$ & $1 \cdot 23(0 \cdot 16)$ & $0 \cdot 30$ & $1 \cdot 26(0 \cdot 17)$ & $0 \cdot 45$ & $1 \cdot 29(0 \cdot 15)$ \\
\hline Alkaline phosphatase activity (IU/l) & $51(9)$ & $0 \cdot 27$ & $58(18)$ & $0 \cdot 001$ & $75(16)$ \\
\hline Oestradiol $(\mathrm{pmol} / \mathrm{l}) \dagger$ & Not measured & & $81(35-400)$ & $0 \cdot 001$ & $34(13-64)$ \\
\hline Urine biochemistry: & & & & & \\
\hline Hydroxyproline:creatinine ratio (mmol:mol) & $22 \cdot 1 \quad(8 \cdot 0)$ & $0 \cdot 33$ & $22 \cdot 6 \quad(6 \cdot 1)$ & 0.05 & $28 \cdot 8 \quad(13 \cdot 2)$ \\
\hline \multicolumn{6}{|l|}{ Bone mineral density: } \\
\hline Lumbar spine $\left(\mathrm{g} / \mathrm{cm}^{2}\right)$ & $1 \cdot 269(0 \cdot 169)$ & $0 \cdot 002$ & $1 \cdot 158(0 \cdot 142)$ & $0 \cdot 001$ & $1.043(0.110)$ \\
\hline Femoral neck $\left(\mathrm{g} / \mathrm{cm}^{2}\right)$ & $1.007(0 \cdot 159)$ & $0 \cdot 007$ & $0.922(0.097)$ & $0 \cdot 038$ & $0.876(0.076)$ \\
\hline
\end{tabular}

subjects and the protocol was approved by the Auckland Hospital Research Ethics Committee.

\section{Results}

Table I gives demographic details of the three groups studied. The postmenopausal controls were of course older than the other two groups. The mean duration of oestrogen deficiency in the DMPA users ( 10.7 years) was similar to that of the postmenopausal controls ( 9.4 years), although the median duration was slightly longer (10 $v 7$ years, respectively). More of the DMPA users were current cigarette smokers than the women in either control group (both $p<0 \cdot 01$, McNemar's test).

Serum oestradiol concentrations in the women using DMPA showed little variation with the time since the previous DMPA injection $(r=0 \cdot 16, p=0 \cdot 41)$ or with age $(r=-0 \cdot 04, p=0 \cdot 83)$. Only four of the DMPA users had serum oestradiol concentrations $>100 \mathrm{pmol} / \mathrm{l}$, but the geometric mean of $81 \mathrm{pmol} / \mathrm{l}$ was significantly higher than that seen in postmenopausal women (34 $\mathrm{pmol} / \mathrm{l} ; \mathrm{p}=0.001)$. The postmenopausal controls differed from the DMPA users in having significantly higher mean values of serum calcium and alkaline phosphatase and urine hydroxyproline:creatinine. Mean values for all the biochemical measurements were similar in the DMPA users and the premenopausal controls (table II).

Table II gives mean values for bone densities in the three groups and figure 1 shows the percentage difference from matched premenopausal control pairs. DMPA users had a bone density in the lumbar spine that was a mean $7.5 \%$ lower than that of matched premenopausal controls $(95 \%$ confidence interval $1.9 \%$ to $13 \cdot 1 \%, p=0 \cdot 002$ ), and bone density in the femoral neck bone was a mean $6 \cdot 6 \%$ lower $(0 \cdot 8 \%$ to $12 \cdot 3 \%, \mathrm{p}=$ $0 \cdot 007)$. When the nine pairs who were discordant for cigarette smoking were eliminated from the analysis the mean difference in bone density between DMPA users and postmenopausal controls remained similar $(6.8 \%$ lower in the lumbar spine, $\mathrm{p}=0.013 ; 6.7 \%$ lower in the femoral neck, $p=0.028$ ). In DMPA users there was no correlation between bone density (expressed as a percentage of that in the paired premenopausal control) and age, duration of DMPA use, or daily cigarette consumption $(\mathrm{r}=0 \cdot 15,0 \cdot 09,0 \cdot 05$ respectively for lumbar spine; $r=-0 \cdot 18,-0 \cdot 11,0 \cdot 17$ respectively for femoral neck). Compared with matched postmenopausal controls, DMPA users had a significantly higher bone density in the lumbar spine (mean difference $8.9 \%(4.3 \%$ to 13.5$), \mathrm{p}=0.001)$ but at the femoral neck there was less difference (mean difference $4 \cdot 0 \%(-0 \cdot 4 \%$ to $8 \cdot 5 \%), \mathrm{p}=0 \cdot 04)$. As expected, there were significant differences between the premenopausal and postmenopausal control groups (fig 1).

In DMPA users and premenopausal controls (but not postmenopausal controls) bone density at both sites was correlated with body mass index (table III). The slopes of the regression lines of body mass index against bone mineral density differed, however, between DMPA users and premenopausal controls $(p<0.05$ for both lumbar spine and femoral neck),

TABLE III - Pearson coefficients $(r)$ and significance $(p)$ of correlations between bone mineral density and body mass index

\begin{tabular}{lcc}
\hline & \multicolumn{2}{c}{ Bone mineral density } \\
\cline { 2 - 3 } & Lumbar spine & Femoral neck \\
\hline Premenopausal controls & $\mathrm{r}=0.64$ & $\mathrm{r}=0.68$ \\
& $\mathrm{p}=0.001$ & $\mathrm{p}=0.001$ \\
DMPA users & $\mathrm{r}=0.47$ & $\mathrm{r}=0.51$ \\
Postmenopausal controls & $\mathrm{p}=0.009$ & $\mathrm{p}=0.004$ \\
& $\mathrm{r}=0.28$ & $\mathrm{r}=0.23$ \\
& $\mathrm{p}=0.14$ & $\mathrm{p}=0.23$ \\
\hline
\end{tabular}
formed for analysis; the results are given as the geometric mean. Biochemical measurements in matched pairs were compared by the paired $t$ test. Paired proportions were compared by McNemar's test, and correlations were calculated by the Pearson method. Informed consent was obtained from all 


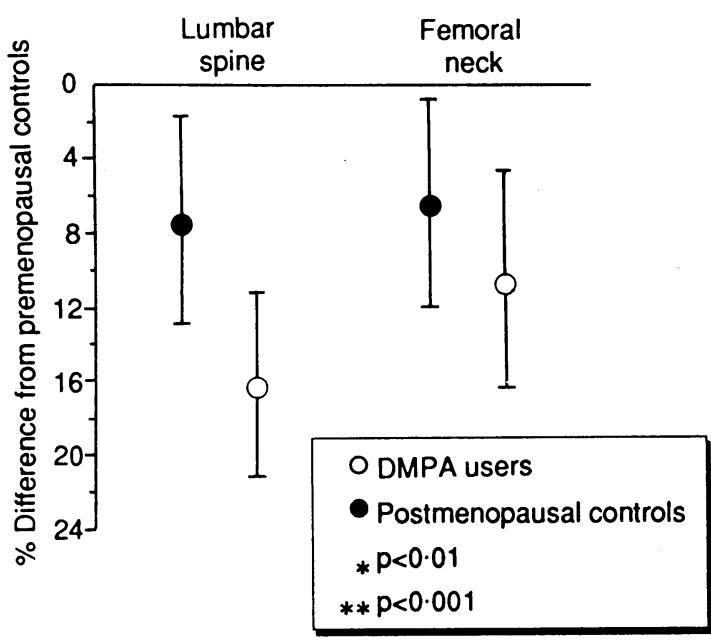

FIG 1-Bone mineral density in DMPA users and postmenopausal controls expressed as mean percentage difference from matched premenopausal controls. Bars indicate $95 \%$ confidence intervals

sharing a common intercept at a body mass index of around 18 (lowest values in the women in this study) and diverging at higher levels. Thus differences in bone density between DMPA users and premenopausal controls were least among women with low body mass indexes and greatest amongst women with high body mass indexes (fig 2). As in the DMPA users, bone density in the postmenopausal controls (expressed as a percentage of the premenopausal controls) correlated neither with the duration of oestrogen deficiency nor with age $(\mathrm{r}=0 \cdot 22,0 \cdot 11$ respectively for lumbar spine, $\mathrm{r}=0 \cdot 20,0 \cdot 11$ respectively for femoral neck).

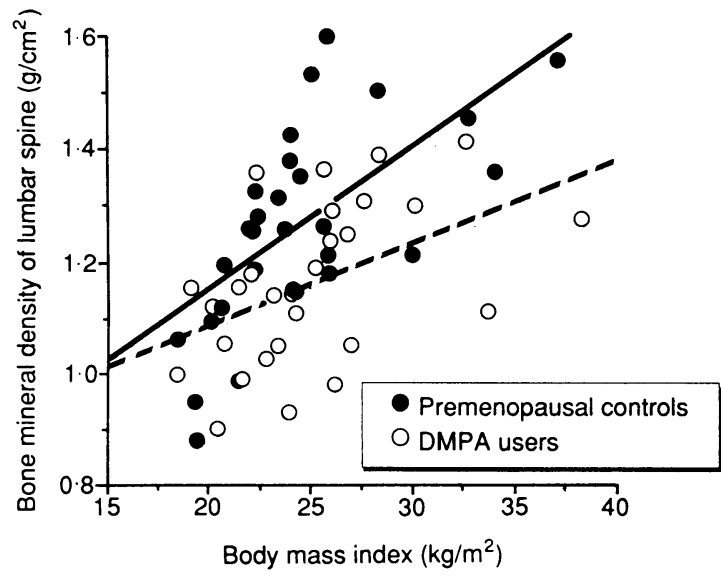

FIG 2-Correlations between bone mineral density in lumbar spine and body mass index for DMPA users and premenopausal controls. Best fit regression lines are shown $(p<0.05$ for difference in slope)

\section{Discussion}

In this study we have shown that women using DMPA long term have lower bone density in the lumbar spine and femoral neck than do premenopausal controls. The controls were matched for several putative determinants of bone mass (age, body mass, and ethnic origin) but not for cigarette smoking. Women who use DMPA are more likely to smoke than women who use other forms of contraception, ${ }^{13}$ and cigarette smoking has been associated with reductions in bone density. ${ }^{14}$ However, the differences in bone density between DMPA users and premenopausal controls could not be accounted for by their cigarette consumption because the effect of DMPA was still present when only the pairs of subjects concordant for smoking were considered.

The degree to which bone density was reduced in the DMPA users is comparable with that seen in other oestrogen deficient states, such as hyperprolactinaemia, in which there is a similar degree of oestrogen deficiency. ${ }^{15}$ The lack of relation between the bone density deficit and the duration of DMPA use does not argue against bone density deficit being an oestrogen deficiency effect. When oestrogen deficiency arises the most rapid bone loss occurs within the first three years. Subsequently the rate of decline of bone density approaches the normal age related rate of fall. ${ }^{16}$ Thus in women who have used DMPA for five years or more the deficit in bone density would not be expected to become more noticeable with longer exposure to oestrogen deficiency. Prospective studies in women starting to take DMPA should help to clarify the dynamics of its effects on bone.

The observed decrease in bone density is not of sufficient magnitude to place otherwise healthy premenopausal women at immediate risk of developing vertebral or proximal femoral fractures, particularly Polynesian women, who have considerably higher bone density than European women. ${ }^{17}$ Reductions of femoral neck bone density of this order have, however, been estimated to increase lifetime risk of fracture by $30-100 \% .^{18}$ In women with pre-existing low bone density the use of DMPA may thus be an appreciable additional risk factor for osteoporosis. Such a projection, of course, assumes that the bone loss associated with DMPA is not reversible on stopping treatment, something that will require prospective studies to determine. If the analogy with other oestrogen deficiency states is correct then some gain of bone density on stopping DMPA might be expected. For example, after cure of hyperprolactinaemia or stopping treatment with gonadotrophin releasing hormone analogues, axial bone loss is partially recovered.$^{67}$

The degree to which bone density was reduced in DMPA users was significantly less than that seen in healthy postmenopausal women with a similar duration of oestrogen deficiency. These women were, of course, considerably older than the DMPA users, but it is oestrogen deficiency rather than age that is the major determinant of bone loss soon after menopause. ${ }^{19}$ In neither the DMPA users nor the two control groups was bone density related to age. The lesser degree of osteopenia in the DMPA users than in the postmenopausal controls may thus reflect their higher serum oestradiol concentrations rather than their younger age, but it is also possible that DMPA itself has direct actions on bone that limit the adverse effects of oestrogen deficiency.

There has been considerable recent interest in the possible anabolic effects of progesterone on bone in premenopausal women. ${ }^{20}$ There is evidence, too, that DMPA and other progestogens have suppressive effects on bone turnover in postmenopausal women, ${ }^{2122}$ and it has been suggested that progestogens could be used to prevent bone loss in postmenopausal women and in subjects treated with glucocorticoids. ${ }^{23-25}$ Our observations suggest that in premenopausal women the effects of inducing oestrogen deficiency outweigh any potential benefit of taking extra progestogens. Not all progestogens are necessarily alike in this regard, and the more androgenic compounds such as norethisterone may have a more protective effect. ${ }^{26}$ In postmenopausal women medroxyprogesterone is less effective than oestrogen in arresting bone loss, ${ }^{27}$ but this does not discount the possibility that in oestrogen deficient states DMPA may have some protective effect on bone.

The mean serum oestradiol concentration in our DMPA users was lower than has been described in published reports. Serum oestradiol concentrations are reported to be similar to those in the early to middle follicular phase, equivalent to $90-290 \mathrm{pmol} / \mathrm{l}$ in our assay. ${ }^{8.10}$ Although these concentrations were lower than expected, they were none the less considerably 
higher than those seen in postmenopausal controls. This raises the issue of how low serum oestrogen concentrations have to be for bone loss to occur. This is difficult to assess directly, but evidence is available from studies of postmenopausal women using oestrogen replacement therapy. Treatment with transdermal oestradiol, which produces serum oestradiol concentrations around $110-160 \mathrm{pmol} / \mathrm{l}$ and a proportionate rise in oestrone concentrations, has been shown to arres bone loss in postmenopausal women. ${ }^{28}{ }^{29}$ Although a definite dose-response relation exists between oestrogen dosage and the bone response when oestrogen is given orally, ${ }^{30}$ this is difficult to translate into serum oestradiol concentrations because several biologically active metabolites appear in the blood. ${ }^{28}$

The increases in serum alkaline phosphatase activity, urine hydroxyproline excretion, and serum calcium concentration in the postmenopausal controls are all recognised features of the menopause ${ }^{3132}$ that reverse with oestrogen replacement therapy. Whether the differences between the DMPA users and the postmenopausal controls in these indices reflect their differing oestrogen states or the direct effects of DMPA on bone turnover is uncertain. The failure to detect significant differences in indices of bone turnover between DMPA users and premenopausal controls may simply reflect the insensitivity of these measurements at low values.

In both DMPA users and premenopausal controls the bone mineral density was strongly correlated with body mass index, but the interaction between body mass index, bone density, and DMPA use was complex, with the effects of DMPA use seeming more pronounced a higher values of body mass index. Although weight gain may be a side effect of DMPA use, this is unlikely to offset significantly the adverse effects on bone density. Alternatively, it may be argued that in underweight women the use of DMPA does not greatly increase thei risk of fracture, but this needs to be confirmed by further studies.

We conclude that long term use of DMPA is associated with significant reductions in bone density in the lumbar spine and femoral neck. Use of DMPA should therefore be considered a potential risk factor for osteoporosis.

We thank the Medical Research Council of New Zealand, New Zealand Lottery Board, Arthritis Foundation of New Zealand, ASB Charitable Trust, Maurice and Phyllis Paykel Trust, and Upjohn for their support of this project, and also Kathleen Bos for preparing the manuscript and Greg Gamble for statistical advice.

1 Cann CE, Genant HK, Ettinger B, Gordan GS. Spinal mineral loss in oophorectomised women: determination by quantitative computed tomography. JAMA 1980;244:2056-9.

2 Redman JR, Bajorunas DR, Wong G, McDermott K, Gneco C, Schneider R, et al. Bone mineralization in women following successful treatment of Hodgkin's disease. Am 7 Med 1988:85:65-72.

3 Cann CE Martin MC Genant HK, Jaffe RB. Decreased spinal mineral

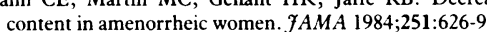

4 Rigotti NA, Nussbaum SR, Herzog DB, Neer RM. Osteoporosis in women with anorexia nervosa. $N$ Engl I Med 1984;311:1601-6.

5 Drinkwater BL, Nilson K, Chesnut CH, Bremmer WJ, Shainholtz S, Southworth MB. Bone mineral content of amenorrheic and eumonorrheic athletes. N Engl f Med 1984;311:277-81.

6 Klibanski A, Greenspan SL. Increase in bone mass after treatment of hyperprolactinemic amenorrhea. $N$ Engl f Med 1986;315:542-6.

7 Matta WH, Shaw RW, Hesp R, Evans R. Reversible trabecular bone density loss following induced hvpo-oestrogenism with the GnRH analogue buserelin in premenopausal women. Clin Endocrinol (Oxf) 1989;29:45-51.

8 Ortiz A, Hiroi F, Stanczyk FZ, Goebelsmann V, Mishell DR. Serum medroxvprogesterone acetate (MPA) concentrations and ovarian function following intramuscular injection of Depo-MPA. I Clin Endcrinol Merab 1977;44:32-8.

9 Jeppsson S, Gershagen S, Johansson EDB, Rannevik G. Plasma levels of medroxyprogesterone acetate (MPA), sex hormone binding globulin, gonadal steroids, gonadotrophins and prolactin in women during long-term use of depo-MPA as a contraceptive agent. Acta Endocrinol 1982;99:339-43.

10 Jeppsson S, Johansson EDB, Sjoberg NO. Plasma levels of estrogens during long-term treatment with depo-medroxyprogesterone acetate as a contraceptive agent. Contraception 1973;8:165-70.

11 Mazess R, Collick B, Trempe J, Borden H, Hanson J. Performance evaluation of a dual-energy $x$-ray bone densitometer. Calcif Tissue Int 1989;44:228-32.

12 Hodgkinson A, Thompson T. Measurement of the fasting urine hydroxyproline:creatinine ratio in normal adults and its variation with age. $\mathcal{F}$ Clin Pathol 1982;35:807-11

13 Jarman H, Kovacs GT, Westcott M. Depo Provera: a profile of current users. Aust NZ F Obstet Gynaecol 1990;30:74-6.

14 Jensen J, Christiansen C, Rodbro P. Cigarette smoking, serum estrogens and bone loss during hormone-replacement therapy carly after menopause. N Engl f Med 1985;313:973-5.

15 Koppelman MCS, Kurtz DW, Morrish KA, Bou E, Susser JK, Shapiro JR, et al. Vertebral body bone mineral content in hyperprolactinemic women. f Clin Endocrinol Metab 1984;59:1050-3.

16 Nordin BEC, Need AG, Chatterton BE, Horowitz M, Morris HA. The relative contributions of age and years since menopause to postmenopausal bone loss. F Clin Endocrinol Metab 1990;70:83-8.

17 Reid IR, Mackie M, Ibbertson HK. Bone mineral content in Polynesian and white New Zealand women. $B M$ J 1986;292:1547-8.

18 Melton LJ, Kan SH, Wahner HW, Riggs BL. Lifetime fracture risk: an approach to hip fracture risk assessment based on bone mineral density and age. 7 Clin Epidemiol 1988;41:985-94.

19 Richelson LS, Wahner HW, Melton LJ, Riggs BL. Relative contributions of aging and estrogen deficiency to postmenopausal bone loss. $N$ Engl f Med $1984: 311: 1273-5$

20 Prior JC, Vigna YM, Schechter MT, Burgess AE. Spinal bone loss and ovulatory disturbances. $N$ Engl f Med 1990;323:1221-7.

21 Mandel FP, Davidson BJ, Erlik Y, Judd HL, Meldrum DR. Effect of progestins on bone metabolism in postmenopausal women. 7 Reproduct Med 1982;27:511-4

22 Selby PL, Peacock M, Barkworth SA, Brown WB, Taylor GA. Early effects of thinyloestradiol and norethisterone trem bone resorption and calcium regulatory hormones. Clin Sci 1985;69:265-71.

23 Prior JC. Progesterone as a bone-trophic hormone. Endocr Reviews 1990;11 386-98.

24 Lobo RA, McCormick W, Singer F, Roy S. Depo-medroxyprogesterone acetate compared with conjugated estrogens for the treatment of postmenopausal women. Obstet Gynecol 1984:63:1-5.

25 Abdalla HI, Harr DM, Lindsay R, Leggate I, Hooke A. Prevention of bone mineral loss in possm, Ling 1985;66:789-92.

26 Riis BJ, Christiansen C, Johansen JS, Jacobson J. Is it possible to preven bone loss in young women treated with lutenizing hormone-releasing bone loss in young women treated with lutenizing ho.

27 Gallagher JC, Kable WT, Goldgar D. Effect of progestin therapy on cortical and trabecular bone: comparison with estrogen. Am f Med 1991;90:171-8.

28 Powers MS, Schenkel L, Darley PE, Good WR, Balestra JC, Place VA Pharmacokinetics and pharmacodynamics of transdermal dosage forms of 17 \& estradiol: comparison with conventional oral estrogens used for hormone replacement. Am f Obstet Gynecol 1985;152:1099-106.

29 Adami S, Suppi R, Bertoldo F, Rossini M, Residori M, Maresca V, et al. Transdermal estradiol in the treatment of postmenopausal bone loss. Bone and Mineral 1989;7:79-86.

30 Horsman A, Jones M, Francis R, Nordin C. The effect of estrogen dose on postmenopausal bone loss. N Engl f Med 1983;309:1405-7.

31 Young $M M$, Nordin BEC. Effects of natural and artificial menopause on plasma and urinary calcium and phosphorus. Lancet 1967; ii: 118-20.

32 Crilly RG, Jones MM, Horsman A, Nordin BEC. Rise in plasma alkaline phosphatase at the menopause. Clin Sci 1980;58:341-2.

(Accepted 25 April 1991)
In the last number of his Archives of Surgery Mr. Jonathan Hutchinson says that he has for many years been in the habit of forbidding fruit to all patients who suffer from tendency to gout. In every instance in which a total abstainer of long standing has come under his observation for any affection related to gout he has found on inquiry that the sufferer was a liberal fruit eater. Fruits are of course by no means all equally deleterious; cooked fruits, especially if eaten hot with added sugar, are the most injurious, the addition of cane to grape sugar adds much to the risk of disagreement. Fruit eaten raw and without the addition of sugar would appear to be comparatively safe. Natural instinct and dietetic tastes have already led the way in this direction, few wine drinkers take fruit or sweets to any extent, and $\mathrm{Mr}$. Hutchinson suggests as a dietetic law that alcohol and fruit sugar ought never to be taken together, and he believes that the children of those who in former generations have established a gouty constitution may, although themselves water drinkers, excite active gout by the use of fruit and sugar.

(British Medical fournal 1891;ii:197) 